\title{
A TEORIA DA SOBERANIA NO TRAUERSPIEL E SEU IMPACTO SOBRE O ABSOLUTISMO SEISCENTISTA
}

Tereza de Castro Callado

\begin{abstract}
A soberania não reina a não ser sobre aquilo que ela é capaz de interiorizar.
\end{abstract}

Deleuze

O rei é o mais justo [dikaiotatos]. O mais justo é o mais legal [nominotatos]. Sem justiça ninguém pode ser rei, mas a justiça é sem lei [aneu nomou dikaiosyne]. O justo é legítimo e o soberano, que se tornou causa do justo, é uma lei viva.

Tratado de Diotogene, parcialmente conservado por Stobeo

\begin{abstract}
RESUMO
Esse artigo deve trazer à tona, a partir do Trauerspielbuch de Benjamin, a cena da corte barroca, enquanto microcosmo da História iluminado no jogo de desvelarencobrir da alegoria, que acaba por revelar, na transgressão ao ideal absolutista de Seiscentos, uma outra teoria da soberania com base no estado de exceção.
\end{abstract}

Palavras-chave: Soberania. Absolutismo. Estado de exceção. Justiça.

\section{THE SOVEREIGNTY THEORY OF TRAUERSPIEL AND ITS IMPACT ON THE SEVENTEENTH-CENTURY ABSOLUTISM}

\begin{abstract}
This article aims on bringing out, from Benjamin Trauerspielbook, the scene of Baroque court as the microcosm of history, illuminated in the game of unveilingcovering of the allegory which ultimately reveals, in violation of the absolute ideal of Six hundred, the theory of sovereignty founded in the state of exception.
\end{abstract}

Keywords: Sovereignty. Absolutism. State of emergency. Justice.

No livro de Walter Benjamin Origem do Drama Barroco Alemão é elaborada uma teoria moderna da soberania não indiferente a certos remanescentes da Teocracia medieval e do caráter anômico do soberano firmado como legibus solutos e já presente no tratado de Diotogene. Esses traços são muitas vezes invisíveis à habitual miopia filológica do pensamento radicado na consciência esclarecida que deixa de perceber a conexão entre a política ideológica contemporânea e a anomia que caracteriza o Estadista liberto de toda subordinação ao direito, para poder atuar como lei viva (nomos empsychos). Foi o que se constatou no momento nazista da história alemã dos meados do século XX. Aquela catástrofe havia sido estruturada 
no "Decreto para Proteção do Povo e do Estado [Verordnung zum Schutz von Volk und Staat]" de 28 de Fevereiro de 1933 e permaneceu por doze anos, até o fim da Segunda Grande Guerra em 1945. Nele atuou a exceção utilizada na teoria do estado de exceção [Ausnahmezustand] que seria dialetizada em uma revolução da política pelo pensador judeu alemão. Para isso Benjamin reativou conceitos de uma doutrina filosófica baseada na codificação histórica, que leva em consideração a soberania do Estado de Criação [Schöpfungsstand], Origem [Ursprung] e Despertar [Erwachen]. A origem [Ursprung] é concebida como uma categoria histórica. E com essa categoria que o governante barroco - o príncipe - se reconhece semelhante ao súdito, realiza a solidariedade que existe naqueles que possuem a soberania sobre os demais viventes. Essa soberania já está situada no estado de criação [Schöpfungsstand], iluminado pelo sol da graça [Gnadensonne]. ${ }^{1}$ Através da faculdade mimética, ao se ver semelhante ao outro, se faz o reconhecimento do monarca no súdito. O sentimento comum aos dois está na condição mortal. ${ }^{2}$ "O estado de criação influencia inequivocamente o próprio soberano" uma vez que na concepção de origem ele permanece criatura entre as demais. Esse plano teológico que estrutura o conceito de soberania é revisado pelo barroco. Ara a mentalidade daquela época "a tentativa de encontrar a origem da realeza no estado de criação ocorre até na teoria jurídica". Mas essa soberania que existe no estado de criação será ameaçada, quando a dialética barroca é fundada sobre a figura do cortesão, que aspira ao poder. A ascensão exige dele "uma rigorosa disciplina interna e uma inescrupulosa atividade" que emanam do espírito, pois, segundo a tese do barroco, o espírito carrega o traço de tirania que se manifesta no conselheiro contra a ordem estabelecida: "o espírito é a faculdade de exercer a ditadura". As investidas do cortesão, que acarretam uma atitude de desilusão radical com relação ao curso do mundo, só têm um similar no calor ardente de sua aspiração ao trono. ${ }^{3}$ Esse processo não acontece sem uma extrema melancolia, no Trauerspiel. Ela é resultado da falta de reflexão. O drama barroco oferece a possibilidade de presenciar esse conflito. Mas ele só é possível pela forma desse teatro que não atinge a síntese, a não ser, no desfecho do martírio, pois o barroco não conhecia a dualidade. ${ }^{4}$ Observa-se que "a atitude não polêmica (der unpolemische Sinn) é uma

1 BENJAMIN. ODBA. p. 108. Ursprung. Opus cit. S. 66.

2 Enquanto o drama protestante alemão acentua os traços infernais do conselheiro, essa figura aparece, na Espanha católica, revestida "da dignidade do "sosiego" que combinam, para compor o ideal de um cortesão eclesiástico e mundano, o ethos católico com a ataraxia antiga. É o caráter ambíguo de sua soberania que funda a dialética, muito barroca de sua posição". BENJAMIN. p. 120. Ursprung... Opus cit. S. 78.

3 BENJAMIN. ODBA, p. 120 Ursprung... Opus cit, S. 78.

4 A Dialektik im Stillstand (dialética na imobilidade) é criada para recepcionar o questionamento, no confronto entre tese e antítese. Essa acareação é espaço em que é possível a visualização de saídas, permitindo que o destino seja reescrito na filosofia política pensada por Benjamin. A "síntese", teria como referência a diluição das guerras e insurreições, na História. A dialética benjaminiana enfrenta o estado de conflito na iniciativa de parar, para um questionamento. Nesse espírito crítico é necessário deter a história para uma revisão. A atitude de "escovar a História a Contrapelo [die Geschichte gegen den Strich zu bürsten]" é recomendada na tese sete de "Sobre o conceito de História" BENJAMIN. Opus cit. 225. Esse processo desvelaria enfim os extremos da história. Na filosofia de Benjamin eles possuem uma significação, como fragmentos, para a composição de uma totalidade. Não se trata de camuflar a realidade, mas de utilizá-la no seu potencial, com o método do "desvio". Benjamin inspira-se em Fourier para mostrar, em um exemplo, uma constituição do mundo, onde "o trabalho social bem organizado teria como proveito (...) que os animais predatórios entrariam a serviço do homem." Nesse novo pensamento, cada

Tereza de Castro Callado - Pós-Doutora pela USP, Professora da Universidade Estadual do Ceará (UECE), Brasileira, residente em Fortaleza - CE, E-mail: $\underline{\text { mterecall@ yahoo.com.br }}$ 
forte característica do Barroco em seu conjunto". 5 A superioridade do drama espanhol é mostrada na capacidade do monarca de interferir na ordem do destino, praticando o bem. Nesse ponto a tese do barroco antecipa a teoria da vontade exposta na "Fundamentação da Metafísica dos Costumes" de Kant. A reflexão é a descoberta do teatro espanhol. No Trauerspiel, ao contrário, os personagens, na metáfora de Lohenstein, oscilam como bandeiras soltas ${ }^{6}$ por não encontrarem uma solução para seus destinos. São movidos por paixões. A ausência da reflexão deixa as coisas à mercê do mundo. A melancolia vem da idéia do abandono e da dispersão, derivados da falta de iniciativa, para a qual os personagens são incapacitados. Suas ações são atitudes bruscas e não atos racionais. E as atitudes, quando existem, não são resultado de uma reflexão, mas de "impulsos físicos vascilantes". ${ }^{7}$ Assim, os reis não podem ser medidos por "padrões medianos". "A época decide que eles têm de ser julgados ou como inteiramente bons, ou inteiramente maus", diz uma passagem de Graciano mostrando que a rigidez oriunda da incapacidade do rei para a reflexão, o transformava em um estereótipo. ${ }^{8}$ Os personagens de El Grego são caracterizados na pequenez de suas cabeças. (...) É coerente com esse estilo que a literatura da época inclusive a poesia épica menos rígida, consiga fixar os gestos mais efêmeros, mas seja impotente com relação ao

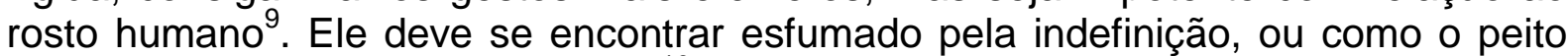
torturado, consumido pelo horror. ${ }^{10} \mathrm{~A}$ dor não permite seu delineamento, mas somente sua representação na imagem claro-escura. A tortura da forma do barroco se deduz do conceito da imanência da história com a natureza. A degeneração da natureza se projeta nos fatos sangrentos e no resultado devastador das guerras e disputas pelo poder, na história. Para o Barroco, a característica do monarca como tirano e como mártir é demonstrada nas duas faces de Janus. ${ }^{11} \mathrm{O}$ conceito de

coisa encontraria o seu lugar:, não sem a interferência responsável da ação do homem. Esta é uma fórmula para comentar o pensamento de Dietzgen para quem "ao conceito corrompido de trabalho corresponde o conceito complementar de uma natureza, que, "está ali, grátis". BENJAMIN. "Sobre o Conceito de História" IN Obras Escolhidas I. Opus cit. p. 228. A Dialektik im Stillstand mostra os meios para isso na imagem dialética. A dialética em repouso é a quintessência do método )Dialektik im Stillstand =- das ist die Quintessenz der Methode. Conferir com BENJAMIN. Das PassagenWerk. Suhrkamp, Frankfurt am Main, 1982. S. 1035.

5 BENJAMIN. ODBA. p. 82. Ursprung... Opus cit. S. 41.

${ }^{6}$ BENJAMIN. ODBA. p. 94. Ursprung... Opus cit. S. 53.

7 BENJAMIN. ODBA. p. 94. Ursprung... Opus cit. S. 53.

8 Ao "inteiramente mau" correspondem o drama do tirano e o terror, e ao "inteiramente bom" o drama do mártir e a piedade. A justaposição dessas formas só parece estranha a quem perde de vista o aspecto jurídico do principado barroco. Se levarmos em conta os ensinamentos da ideologia, tais formas são rigorosamente complementares." BENJAMIN. ODBA. P. 93. Ursprung...Opus cit. S. 51.

9 BENJAMIN. ODBA. p. 94. Ursprung... Opus cit. S. 53.

${ }^{10}$ BENJAMIN. ODBA. p. 94. Ursprung. Opus cit. 53.

${ }^{11}$ Conta o mito que, com o passar dos séculos e com o progresso da civilização, Apolo, deus das artes, teve um lugar de honra. Só Jano, o antiqüíssimo nume bifronte (ou quadrifonte), não encontrou no Olimpo um deus parecido com ele. Jano era uma divindade cujo nome lembrava a porta (em latim, ianua), como para significar o misterioso poder que abre e fecha o destino, que vigia a entrada e a saída da vida - e eis a significação da dupla face -, o deus do dia e da noite, do começo e do fim. Por sua idade veneranda era considerado o pai dos deuses (Janus pater) a quem era consagrado, depois da reforma do calendário, o primeiro mês do ano (januarius, janeiro). Seu templo, dos mais arcaicos, erguido pelo rei Numa Pompílio, situava-se no Fórum e as portas ficavam abertas durante as guerras e fechadas em tempo de paz (...) Quirino, o primitivo deus da guerra, estava portanto em conexão direta com Jano, como uma emanação dele. NARDINI, Bruno. Mitologia - o primeiro encontro. São Paulo, Círculo do Livro, 1982, p. 11-113.

Tereza de Castro Callado - Pós-Doutora pela USP, Professora da Universidade Estadual do Ceará (UECE), Brasileira, residente em Fortaleza - CE, E-mail: mterecall@yahoo.com.br 
história naturalizada tem uma ambivalência criativa: ela revela a criatura, na virtude de manter igualmente o equilíbrio a sua volta, é quando se trata de controlar as emoções: "a função do tirano é a restauração da ordem, durante o estado de exceção: uma ditadura cuja vocação utópica será sempre a de substituir as incertezas da história pelas leis de ferro da natureza". ${ }^{2}$ Aqui a virtude e as contingências religiosas da época, privando o homem da transcendência, atuam no sentido de uma dispersão, para, em meio a um estado de "tortura moral" intensificar uma busca positiva à interiorização. $\mathrm{O}$ socratismo de Benjamin favorece o encontro de uma força em si. Ela corresponde àquela da ordem messiânica que continua atuando de geração em geração. Benjamin comenta também sobre "um conhecimento interior do que está por vir" ${ }^{\prime 3}$ do qual, abrem mão, aqueles que perguntam a outrem, sobre seu futuro. No interesse da explicação da relação da filosofia com a religião, não há nada que possa impedir Benjamin de repetir o conteúdo da filosofia, no que diz respeito ao esquema que ela assumiu anteriormente ao sistema. Trata-se ainda de relacionar três pontos: teoria do conhecimento, metafísica e religião. ${ }^{14} \mathrm{~A}$ filosofia inteira se dissolve em metafísica e teoria do conhecimento, continua Benjamin. Uma contingência da época do barroco que eleva a condição do príncipe à imposição de governar, mantendo a ordem e a harmonia entre os súditos, e impedindo a qualquer preço o conflito, se encontra no princípio de autoridade, que o faz senhor das criaturas, autoridade esta já incluída no Estado de Criação, em forma de soberania. Esta concepção inclui toda a criatura. Pois a soberania deve fazer valer o sentido do outro. As significações alegóricas estão proibidas pela culpa de encontrar em si mesmas o sentido. ${ }^{15}$ Essa superação só se dá no confronto com a própria fragilidade no monarca barroco, no reconhecimento da mesma limitação. É no estado de precariedade, na ausência, no que está por completar (Unabgeschlossen) que a verdade se revela, e nunca na lassidão do conforto, nem na abastança ou no já realizado (Abgeschlossen), que para Benjamin é fonte de sofrimento, pois prescinde da ação do homem. A filosofia de Benjamin se diferencia do sistema no século XIX, na medida em que aquele método preenchia todas as zonas do pensamento com elementos conceituais e nuances terminológicas sem deixar nenhum espaço para a mobilização do Ser (Dasein) na sua singularidade. Essa singularidade é exercida pelo monarca barroco. Ela se manifesta na atitude exemplar que pode constituir lei, na concepção kantiana. ${ }^{16}$ É essa a lei que deve desestabilizar a lei que é apenas código. Para o soberano permanecer no reino ele se faz fidedigno, confiável. Mas sua atitude nem sempre é visível. A decisão é interior e depende exclusivamente dele: ele é o mártir, o estóico radical, e seu momento de provação se dá durante um conflito com a coroa ou uma disputa religiosa cujo desfecho pode significar para ele a tortura e a morte.

\footnotetext{
${ }^{12}$ BENJAMIN. ODBA. p. 97. Ursprung... Opus cit. S. 55.

${ }^{13}$ BENJAMIN. Rua de Mão Única. Opus cit. p. 63.

${ }^{14}$ BENJAMIN. "Über das Programm der kommenden Philoso-phie." IN Gesammelte Schriften. II, 1. 1977. S. 168-169

${ }^{15}$ Dem allegorisch Bedeutenden ist es durch Schuld versagt, seine Sinnerfüllung in sich selbst zu finden. BENJAMIN. ODBA. p. 247 Ursprung... Opus cit. 200.

16 "Devo proceder de maneira que eu possa querer também dque a minha máxima se torne uma lei universal" KANT, Immanuel Fundamentação da metafísica dos costumes (Trad. Paulo Quintela) Lisboa, Edições 70, 1997. p. 33. Aqui, no imperativo categórico kantiano, "o dever não é "uma vã ilusão" ou "um conceito quimérico". Ele coincide com "a comum razão humana (Menschenvernunft) nos seus juízos práticos".
}

Tereza de Castro Callado - Pós-Doutora pela USP, Professora da Universidade Estadual do Ceará (UECE), Brasileira, residente em Fortaleza - CE, E-mail: mterecall@yahoo.com.br 
Ao avaliar esse período com vistas a uma teoria da soberania observa Benjamin que "um novo conceito de soberania se formou no século XVII, uma confrontação final com a doutrina jurídica da Idade Média. O velho problema do tiranicídio tornou-se o ponto focal desse debate", devido ao aparecimento do "usurpador". ${ }^{17} \mathrm{Em}$ uma situação de guerras quem reina tem a inclinação a atitudes radicais. No entanto essa iniciativa era incompatível com o pensamento da época:

o elemento despótico e mundano, emancipando-se da rica sensibilidade vital da Renascença, propõe o ideal de uma estabilização completa, de uma restauração tanto eclesiástica como estatal, com todas as suas conseqüências. Uma delas é a exigência de um principado cujo estatuto constitucional seja a garantia de uma comunidade próspera, florescente tanto do ponto de vista militar como científico, artístico e eclesiástico. No pensamento teológico-jurídico, tão característico do século, manifesta-se o efeito de retardamento provocado por uma superexcitação do desejo de transcendência, que está na raiz dos acentos provocativamente mundanos e imanentistas do Barroco. Pois ele está obcecado pela idéia da catástrofe como antítese ao ideal histórico da Restauração. É sobre esta antítese que se constrói a teoria do estado de exceção. ${ }^{18}$

A função do príncipe é a restauração da ordem, durante o estado de exceção: uma ditadura cuja vocação utópica será sempre "a de substituir as incertezas da história" ${ }^{19}$ com a força de sua natureza interior. No estado de exceção quando ele é obrigado a decidir, surge a antítese para ofuscar sua soberania. Pois sendo ele senhor das criaturas ele próprio permanece criatura. Aqui a dialética na imobilidade (Dialektik im Stillstand) torna visível a antinomia. Essa categoria de criatura inibe a sublevação, ela própria é que conduz ao ideal ascético na atitude do governante no Trauerspiel: "Assim como o Cristo-Rei sofreu em nome da humanidade, o mesmo ocorre (...) com o monarca em geral". ${ }^{20}$ No palco aparece, ainda recortando uma paisagem no fundo, uma grande coroa encimando a seguinte frase:

\footnotetext{
${ }^{17}$ A igreja havia condenado o tirano usurpador, mas a questão consistia em decidir, de quem poderia partir o sinal para eliminá-lo: do povo, do rei rival, ou exclusivamente da Cúria. A posição da igreja em nada perdera de sua atualidade pois num século de guerras religiosas o clero tinha boas razões para manter-se fiel a uma doutrina que lhe dava armas contra príncipes hostis. O protestantismo recusava as pretensões teocráticas dessa doutrina e não deixou de denunciar suas conseqüências, por ocasião do assassinato de Henrique IV. Com o aparecimento dos artigos galicanos, em 1682, caíram os últimos bastiões da teoria teocrática do Estado; a inviolabilidade absoluta do soberano foi defendida com êxito diante da Cúria. Apesar das diferentes posições assumidas pelos partidos, essa doutrina extrema do poder do Príncipe teve sua origem na Contra-Reforma, e foi no início mais inteligente e mais profunda que sua versão moderna. Ao passo que o conceito moderno de soberania resulta no exercício pelo Príncipe de um poder executivo supremo, o do Barroco nasce de uma discussão sobre o estado de exceção e considera que impedi-lo é a mais importante função do Príncipe".BENJAMIN. ODBA. p. 89. Ursprung... Oups cit. S. 47.

${ }^{18}$ BENJAMIN. ODBA. p. 89. Ursprung... Opus cit. S. 47.

${ }^{19}$ BENJAMIN. ODBA. p. 97. Ursprung... Opus cit. S.55.

20 "Se a justiça é o objetivo da lei, a lei é obra do príncipe e o príncipe a imagem de Deus, pela mesma razão é necessário que a lei do príncipe seja feita na medida da lei de Deus" No pensamento de Bodin só quando a lei ocorre dessa forma é que ela pode enunciar a justiça. De outra forma a lei é mandato arbitrário sem relação com a consciência. Bodin chama a esse último aspecto da lei, momento voluntarista com o qual ele nomeava os poderes feudais e estamentais. BODIN. Jean. Los seis libros de la Republica Madrid. Editorial Tecnos, 2000. p. 66.
}

Tereza de Castro Callado - Pós-Doutora pela USP, Professora da Universidade Estadual do Ceará (UECE), Brasileira, residente em Fortaleza - CE, E-mail: mterecall@yahoo.com.br 
esse fardo parece uma coisa para aquele que o carrega, e outra para os que se ofuscam com seu brilho enganador. Estes jamais conheceram o seu peso, mas o outro (o monarca) tem experiência do sofrimento que lhe traz. ${ }^{21}$

Por isso esse século vê a atitude do governante caracterizada pela apatia (amáucia), ausência de paixões, que era, na verdade, a melancolia. A inércia motivada pelo desânimo diante do sentimento de impotência para governar, imerge o príncipe na melancolia. "Ele deve ser um exemplo perfeito de todas as virtudes (ein Exempel (...) aller vollkomenen Tugenden)", assim deve ser o "herói", embora reconheça-se incapaz de sê-lo. ${ }^{22}$ O "Viver com retidão", que se desenvolveu na época se contrapõe ao taedium vitae das naturezas mais ricas. Pois os que exploravam mais profundamente as coisas se viam na existência como num campo de ruínas, cheio de ações parciais e inautênticas. A própria vida protestava contra isso. Ela sente profundamente que não está aqui para ser desvalorizada pela fé. Ela se horroriza profundamente com a idéia de que a existência inteira poderia transcorrer dessa forma. Sente um terror profundo pela idéia de morte". Aqui entra a importância do luto para se compreender essa época: "cada sentimento está ligado a um objeto apriorístico". Mas esse objeto só pode ser concebido "na sua fenomenologia"23, o que intensificava o sentimento de luto da época, "determinado por uma surpreendente tenacidade de intenção" que tinha seu similar somente na profundidade do amor. Só havia um espaço entre a ausência de paixões, a

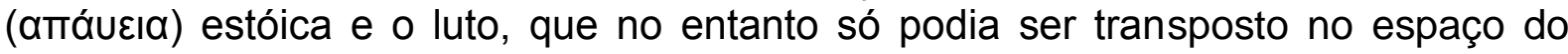
cristianismo. Ele explica a iniciativa apreciada pela época para "libertar os grandes dos enredamentos da história (Verstrickerung der Geschichte), no qual o barroco só via a dimensão política (in welcher der Barock nur Politik sah)". ${ }^{24} \mathrm{Na}$ teoria da soberania de Benjamin, saber governar está mais na capacidade de mobilização, na versatilidade para contornar os acontecimentos, onde o Estadista não pode dispensar os recursos até mesmo os da imaginação, como a presença de espírito (Geistesgegenwart). O conhecimento da natureza humana, o preparo para acatar e compreender o imprevisível, bem como a agilidade mental para a atitude certa formam a estrutura que habilita o governante a reinar sobre os demais, em suma, seu mérito está na capacidade para lidar com os fatos. ${ }^{25}$ Nessa função não se pode deixar de valorizar a moralidade. A filosofia política benjaminiana não perde de vista a análise da moral kantiana, nem o pensamento político dos antigos. Para se mudar o Estado, recomenda Bodin, deve-se ter em conta o natural dos homens. Ele relembra a adaptação dos governantes a cada costume de um povo. ${ }^{26} \mathrm{Na}$ concepção benjaminiana de estadista deduzida do confronto entre o parlamentarismo de Weimar e o absolutismo seiscentista vêm à tona a experiência

${ }^{21}$ BENJAMIN. ODBA. p. 96. Ursprung... Opus cit. S. 54.

22 "O herói... deve ser um exemplo perfeito de todas as virtudes, e afligir-se com a infidelidade de amigos e inimigos, mas de tal forma que se mostre generoso em todas as circunstâcias, e supere corajosamente os sofrimentos, que manifestam em suspiros, elevação da voz e muitas lamentações". Essa idéia poderia ser aplicada a Cristo. BENJAMIN. ODBA. pp. 95-96. Ursprung... Opus cit. S. 54.

${ }^{23}$ BENJAMIN. ODBA, p. 162. Ursprung... Opus cit. S. 120.

24 BENJAMIN. ODBA. p. 165. Ursprung... Opus cit. S. 122.

${ }^{25}$ BENJAMIN. ODBA. p. 118. Ursprung... Opus cit. S. 76.

${ }^{26}$ BODIN Jean. Los seis libros de la Republica (Traduccion Pedro Bravo Gala), Madrid. Editorial Tecnos. 2000, p. 214.

Tereza de Castro Callado - Pós-Doutora pela USP, Professora da Universidade Estadual do Ceará (UECE), Brasileira, residente em Fortaleza - CE, E-mail: mterecall@yahoo.com.br 
do Estadista com a história. Esse conceito não pode prescindir da experiência, que contrapõe a autoridade ao poder. Autoridade no âmbito político é veiculada à experiência, ao conhecimento das razões, e ao esclarecimento, enquanto o poder alia-se à violência. Autoridade (Autorität) pode ser uma fonte de poder que mostra o caminho e orienta, mas nunca poder (Gewalt) que impõe e desagrega. A autoridade atua com intensidade moderada - porque é administrada pela moral. A autoridade estabiliza, enquanto o poder é coercitivo, persuade, convence pela força. Contrariando as disposições da soberania na era profana do barroco, Calderón de la Barca constrói um monarca que detém, em sua forma secularizada, o poder de redimir (als säkularisierte Heilsgewalt) ${ }^{27}$, ostentando dessa forma a dignidade ética (ethische Würde) quando se confronta o drama barroco com o drama espanhol, especialmente o drama que sofreu o rigor da moral luterana, impedindo a confrontação entre a natureza mortal do príncipe e a função sacrossanta, ou seja a dignidade de que era investido como representante de Deus na terra. Aquele dramaturgo espanhol não pode renunciar a uma saída do impasse e com esse objetivo seu teatro desenvolve a arte da prestidigitação e do ilusionismo: é o jogo de espelhos, através do qual o recurso cênico impressiona, o que serve de metáfora e sugestão para que a virtude possa da mesma forma assegurar-se da transcendência. Fica nessa metáfora a alusão irônica às condições materialistas e inconsistentes da interioridade derivadas da atmosfera fantasmagórica a que a cidade moderna se submete. E aqui é necessário citar Senancour por considerar a cidade absolutamente desnecessária ao homem. Ali no século XVII, a reflexão em Calderón, é capaz de manipular a ordem do destino (Schicksalsordnung): mesmo que para Segismudo, personagem de La vida es sueño, sua realização oscile entre sonho e realidade, ele prescreve fazer o bem. ${ }^{28} \mathrm{O}$ estado de sonho é tão forte que atinge e macula a vida desperta: "no sonho a moralidade não perde os seus direitos (Sittlichkeit ist in ihm zuständig): sonho ou verdade não importa. Devo fazer o Bem (Recht thun muss ich) de qualquer modo", pensa o protagonista. É a reflexão que salva a alma da subjetividade. Olgária vê uma diferença entre a ética para Aristóteles e a ética para Kant. ${ }^{29}$ Para Aristóteles o ato virtuoso deve ser agradável, ou pelo menos, sem sofrimento. Para Kant, ao contrário, "o fazer-bem por dever, mesmo que a isso não sejamos levados por nenhuma inclinação, e até se oponha a ele uma aversão natural e invencível, é "amor prático e não patológico", que reside na vontade e não na tendência da sensibilidade, em princípios de ação e não em compaixão lânguida. E só esse amor é que pode ser ordenado". 30 A vontade do monarca barroco permanece no plano do querer, quando ela é neutralizada pela indecisão. A ausência de ação conduz a história à catástrofe. Portanto, a vontade deve levar à ação. Sabe-se que o Trauerspiel evolui na crescente perplexidade da criatura, como resultado de uma sensibilidade ao antagonismo, e desse modo mergulha na desesperança da condição humana. Essa perplexidade terrena do homem se exprimiria de forma incisiva e se estabeleceria, quando contraposta "ao poder hierárquico do príncipe", se o moralismo de Lutero tivesse permitido uma confrontação entre esses dois aspectos da condição do monarca. O que marca de

\footnotetext{
${ }^{27}$ BENJAMIN. ODBA. P. 104. Ursprung... Opus cit. S. 62.

${ }^{28}$ BENJAMIN. ODBA. P. 107. Ursprung... Opus cit. S. 65.

${ }^{29}$ MATOS. Olgária Chain Féres. O Iluminismo Visionário. Opus cit. p. 133.

${ }^{30}$ KANT. Immanuel. Fundamentação da Metafísica dos Costumes. (Trad. Pulo Quintela), Lisboa, Edições 70, 1995. p. 30.
}

Tereza de Castro Callado - Pós-Doutora pela USP, Professora da Universidade Estadual do Ceará (UECE), Brasileira, residente em Fortaleza - CE, E-mail: mterecall@ yahoo.com.br 
forma geral a atitude do monarca é a condição régia, a insígnia, o emblema e não a convicção da verdadeira soberania. A imposição de sua função de governar um povo, diante das condições abjetas que espreitam o seu cargo e que fazem da corte o local de conspiração é encarnada na figura do intrigante. Dessa forma é na esteira do jogo com o seu universo interior, com o controle da alma, que se desenvolve a política encenada no drama barroco. Essa disputa só pode ser vencida no princípio da vontade, que o submete a um plano de interioridade traçado com o rigor estóico. A situação ex-officio surge na realização moral. Ela se desenvolve na doutrina da rex imago aequitatis da teologia medieval ${ }^{31}$ embora só possa aparecer sob o plano do profano, na trajetória do barroco. Ela reúne aspectos ontológicos anteriores de uma critomimesis real e torna-se manifesto na relação do rei com o direito e a justiça, que substituía o status anterior em relação ao sacramento e ao Altar, intuída na idéia de sacerdócio real investida da própria lei". ${ }^{32}$ Mas esse aspecto da soberania no Barroco, não aparecia como síntese de uma inviolabilidade precedida da aura que a teocracia concedia ao soberano. Antes a queda do monarca era vista pelo barroco como parte do processo histórico.

Para se compreender a lógica política benjaminiana é preciso percorrer, em algumas instâncias, não só os detalhes, em que está inserido também o poder do tirano no Trauerspiel, mas também seu aspecto antitético. Sua configuração não se distancia dos elementos já visualizados pela filosofia de Descartes: "o dualismo não é o único elemento barroco de Descartes. Sua teoria das paixões é altamente significativa como doutrina das influências entre corpo e alma". ${ }^{33} \mathrm{O}$ barroco assimilou, até as últimas conseqüências, na figura real, a contradição, a que está sujeita a condição humana. A primeira diz respeito à superioridade do espírito sobre o corporal. Se o espírito hegeliano é razão pura e fiel a si mesma, é na participação com o mundo através do corpo, no Trauerspiel, que ele se exterioriza. Na Forma do Trauerspiel esses extremos se manifestam de forma evidente para assumirem a dialética do governar. Na constituição do soberano barroco a dor física é a base imediata para o aparecimento dos afetos fortes (Heftige Affekte). É a suspensão dos afetos realizadora da soberania ex-officio do monarca, ou mesmo a mobilização dos afetos em direção a outros, em que se estrutura a alteridade. $O$ estado de exceção na alma permite ao tirano permanecer um modelo até sua queda (der Tyran bleibt

\footnotetext{
31 “Em certos capítulos muito citados do início do Livro Quarto do Policraticus, João de Salisbury desenvolveu sua doutrina do rex imago aequitatis. A metáfora do rei como uma "Imagem da Eqüidade" ou "Imagem da Justiça" é muito antiga; nem por isso invalida, por si só em um nenhum sentido, a noção do rex imago Christi ou abusa dos seus limites - afinal, Christus ipse ipsa iustitia. A versão de João de Salisbury sugere apenas uma ligeira variação do antigo tema, um desvio aparentemente insignificante do aspecto litúrgico para o aspecto legal de Cristo conforme representado pelo monarca. No caso de João de Salisbury, essa variação torna-se assim patente, devido apenas à sua incorporação de máximas do Direito Romano, ao monumental edifício de seu pensamento, onde se fundiam elementos hierocráticos e humanistas. João de Salisbury tentava resolver o que hoje pode parecer autocontraditório ou um esforço pra encontrar a quadratura do círculo, já que atribuía a seu Príncipe o poder absoluto e, ao mesmo tempo, limitação absoluta pela lei.A essência dessa pretensa antinomia é exposta no cabeçalho de um capítulo onde se lê: "Que o príncipe, embora não esteja limitado pelas amarras da Lei, é, contudo, o servo da Lei, bem como da eqüidade; que ele é portador de uma pessoa pública e que derrama sangue sem culpa". KANTOROWICZ. Os Dois Corpos do Rei. Opus cit, p. 75-76.

32 KANTOROWICZ. Os Dois Corpos do Rei. Opus cit. p. 75

${ }^{33}$ BENJAMIN. ODBA. p. 241. Ursprung... Opus cit. S. 193.
}

Tereza de Castro Callado - Pós-Doutora pela USP, Professora da Universidade Estadual do Ceará (UECE), Brasileira, residente em Fortaleza - CE, E-mail: mterecall@yahoo.com.br 
bis in seinen Untergang Modell). ${ }^{34} \mathrm{E}$ nesse comportamento resolve-se o malentendido sobre a política absolutista. Os críticos não conseguiram ler a força política que emanava da constituição dessa forma secularizada para medir a política atual, da mesma maneira que o padrão de avaliação do século XVIII também não alcançou a força interpretativa da estética do Trauerspiel como forma. O drama barroco é uma idéia. O juízo do século XVIII - estruturado na teoria aristotélica amplamente aceita, portanto, nos parâmetros para medir a tragédia clássica, acabou vendo no drama a projeção deformada "daquele gênero dos antigos e em seu exagero retórico uma distorção do nobre pathos helênico". ${ }^{35}$ A falha desse ponto de vista consiste em não atentar para o caráter ímpar da expressão barroca moldado nas contingências históricas, para o enredo de suas ações principais e de Estado (Haupt- und Staatsaktionen). Mas é preciso acrescentar que a falta de alcance do julgamento para o drama alemão da Contra-Reforma se deve também à forma indócil, orientada na fidelidade à violência do conteúdo, radicado na ideia de vazio ${ }^{36}$, quando as ações humanas são privadas de todo valor, o que, por sua vez, gera a concepção de destino - onde a vontade, dirigida pela moral luterana, não tem mais por que agir, difundindo simultaneamente a idéia de enigma, no olhar interpretativo sobre o mundo. ${ }^{37}$ Vem daí a necessidade de uma visão panoramática da história, a qual o barroco não pode renunciar. Visto como a "renascença tosca da tragédia", pela geração posterior, ficou por longo tempo obscurecido o conteúdo temático da dramaturgia do século XVII alemão, que tinha, na decadência da história estampada nas lutas de defesa pela religião - o elemento mais autêntico para expressar a degradação imanente à vida natural. ${ }^{38}$ Enquanto na tragédia 0 personagem se encontra sob o impacto do destino individual, que deve expiar com a morte para transcender como herói ${ }^{39}$, no drama, se as configurações circulam entre o vício e a virtude, é por imposição da condição de criatura, sem direito a nenhum apelo ao sobrenatural. ${ }^{40} \mathrm{~A}$ vida é habitada pela degradação e pela morte, na

${ }^{34}$ BENJAMIN, ODBA. p. 168. Ursprung... Opus cit. S. 124.

${ }^{35}$ Die Fabel ihrer Haupt- und Staatsaktionen entstellte das antike Königsdrama, der Schwulst das edle Pathos der Hellenn und der blutrünstige Schlusseffekt die tragische Katastrophe. BENJAMIN. ODBA, p. 72 Ursprung_Opus cit, S. 32.

${ }^{36}$ Jeder Wert war den menschlichen Handlungen genommen. Etwas neues entstand: eine leere Welt BENJAMIN. ODBA. p. 162. Ursprung... Opus cit. S. 119.

${ }^{37}$ Para Benjamin, Calderón soube dar ao drama uma forma flexível, o que não aconteceu na dramaturgia alemã desse período: das deutsche Drama der Gegenreformation hat niemals jene geschmeidigte, jedem virtuosen Griff sich bietende Form gefunden, die Calderón dem spanischen gab. BENJAMIN. ODBA. p.71 Ursprung. Opus cit. S. 31.

${ }^{38}$ É nesse ponto que o drama difere da tragédia, como este gênero é prescrito por Aristóteles, na Poética. Se a tragédia antiga se envolve com o heroísmo passado, por ter como objeto o mito o Trauerspiel (drama barroco) tem a história como conteúdo, ou seja, sua motivação é "valorizar as virtudes principescas, denunciar os vícios principescos, explicar as manobras diplomáticas e as maquinações políticas, vendo no monarca a figura principal (die Bewährung der fürstlichen Tugenden, die Darstellung der fürstlichen Laster, die Einsicht in den diplomatischen Betrieb und die Handhabung aller politischen Machinationen, welche den Monarchen zur Hauptperson des Trauerspiels bestimmt)." BENJAMIN, ODBA. p. 86. Ursprung. Opus cit. S. 45.

${ }^{39}$ O herói trágico perde a inocência do pertencimento ao todo e ganha a dor (fecha-se na solidão glacial do eu. Sentindo-se separado do cosmo vai buscar em si o parâmetro. Ele percebe num átimo que é superior aos deuses. Olgária Matos. Aula de pós-graduação. Teoria das Ciências Humanas. USP. 04/04/2000.

${ }^{40}$ A compreensão de que o "Estadista é aquele que sabe lidar com os fatos" por um conhecimento profundo da natureza humana, aproxima essa teoria política, do pensamento de Platão sob dois aspectos. O Político de Platão tem como pré-requisito a filosofia, e, como filósofo, possui o

Tereza de Castro Callado - Pós-Doutora pela USP, Professora da Universidade Estadual do Ceará (UECE), Brasileira, residente em Fortaleza - CE, E-mail: mterecall@yahoo.com.br 
experiência da guerra dos trinta anos - 1618 a 1648 - resultado do conflito civilreligioso, como conseqüência da imanência entre natureza e história, isto é, desvelase na civilização a facies hipocratica ${ }^{41}$, ou seja, a história do sofrimento do mundo, que tem sua exteriorização máxima no cadáver. O cadáver é o supremo adereço cênico ${ }^{42}$, sem o qual a apoteose do drama era inconcebível. Era função da figuração do tirano prover a cena com cadáveres. Esse expediente deve significar também que o destino é fechado na mentalidade do barroco, onde toda a existência só podia responder na forma de um enigma (als Rätselfrage). ${ }^{43} \mathrm{O}$ luto emergente desse estado de coisas será "estado de ânimo em que o sentimento reanima o mundo vazio para receber desse mundo uma compensação enigmática em forma de máscara. Pois é também com aqueles elementos teológicos remanescentes, ainda no barroco, do cristianismo medieval que será dialetizada a morte. A realidade inconteste do barroco buscará uma decifração para ela na significação de vida. $A$ tendência a oscilar entre extremos faz parte do artifício de desvelar e esconder de uma disposição anímica voltada para a história natural, uma vez que toda a história era desprovida de virtude, na mentalidade do século XVII. A crítica era incapaz de ver o lado moral da atitude soberana, no estado de exceção. A falta de substância sofrida pelo barroco e a desolação (taedium vitae) viam na criatura a moldura de um espelho projetando distorções ${ }^{4 \overleftarrow{4}}$ isto é, a percepção que o barroco nutria da criatura não camuflava o aspecto abjeto da condição humana - os vícios. A história trazia essa experiência para a cultura de cada povo. A expressão histórica cunhada no estado de guerra é interpretada como projeção da physis, local de degeneração orgânica e de degradação moral que encontra sua origem da concepção teológica da queda. No barroco, o mundo se esvazia porque é privado de sentido. E quanto maior a pretensão ao sentido, "maior a sujeição à morte, no drama barroco, porque é a morte que grava mais profundamente a tortuosa linha de demarcação entre physis e significação". ${ }^{45}$ Ironicamente, apesar de tudo conspirar contra a criatura, somente de sua natureza, suscetível de corrupção, se pode esperar uma atitude moral. Aqui interfere a fé do barroco realizada em um plano completamente profano, onde a secularização transmite a indiferença à possibilidade de realização transcendente. Por isso se diz que essa época foi contemplada com a "hegemonia cristã incontestada". Diante da pressão do tempo que tudo consome, a vida interior dos personagens precisa realizar-se interiormente na condição de criatura. $O$ soberano que é visto como "expoente da história", na concepção naturalizada, deve sustentar o acontecimento como se sustenta um cetro. Esse pensamento não é peculiar a um dramaturgo, mas é derivado de certas concepções do direito constitucional, que acaba recriando o conceito de soberania. Não se pode deixar de ver na sua fundação a influência da doutrina jurídica da Idade Média, que não se exterioriza

conhecimento da essência (ousía). Em Benjamin esse conhecimento recorre também à experiência.

41 "In der Allegorie (liegt) die facies hippocratica der Geschichte als errstarte Urlandschaft dem Betrachter vor Augen ( $O$ observador vê na alegoria o lado decadente da história como protopaisagem petrificada)", ou seja, a história no seu aspecto orgânico, suscetível à doença, à degeneração. BENJAMIN. ODBA. P. 188. Ursprung Opus cit. S. 145.

${ }^{42}$ Für das Trauerspiels des XVII Jahrhunderts wird die Leiche oberstes emblematisches Requisit schlechthin. BENJAMIN. ODBA. p. 242. Ursprung. Opus cit. S. 194.

${ }^{43}$ BENJAMIN. ODBA. p. 188. Ursprung... Opus cit. S. 145.

${ }^{44}$ BENJAMIN. ODBA. p. 114. Ursprung ... Opus cit. S. 72.

${ }^{45}$ BENJAMIN. ODBA. p. 188. Ursprung... Opus cit. S. 145.

Tereza de Castro Callado - Pós-Doutora pela USP, Professora da Universidade Estadual do Ceará (UECE), Brasileira, residente em Fortaleza - CE, E-mail: $\underline{\text { mterecall@ yahoo.com.br }}$ 
oficialmente no barroco, mas lança uma luz tênue sobre o sistema jurídico do principado barroco. Na noção corrente de soberania, o ato de reinar está visceralmente ligado a uma concepção ditatorial, mas o parêntese aberto pelo pensamento teológico jurídico manifesta-se "no retardamento provocado por uma surperexcitação do desejo de transcendência". ${ }^{46}$ É esse retardamento, o espaço aberto, que, impedindo a síntese, ilumina o processo, em que se dá "a soberania de fato".

É o barroco que mais sente a presença esmagadora da ordem em que se insere a condição humana: a dualidade, a contradição, sem a qual é impossível reconhecer e compreender a verdadeira ordem do mundo. Poderíamos dizer que ele consiste em um heroísmo anônimo (se fosse permitida ao barroco falar de heroísmo), na tentativa exasperada de aproximar a ordem do movimento. O barroco - ao contrário do que faz o classicismo, que insiste em uma harmonia para o cosmos - não desmente, como faz aquele movimento, "a tensão entre mundo e transcendência (Spannung zwischen Welt und Transzendenz)". ${ }^{47}$ O drama é centrado na vida histórica, que carrega, por sua vez a ideia de organicidade - uma paixão do barroco. No Trauerspiel, como pensa Opitz ${ }^{48}$, o monarca não assume uma posição central

\begin{abstract}
para protagonizar um confronto com Deus e o destino, ou para corporificar um passado imemorial, como chave para uma comunidade nacional viva, e sim para confirmar as virtudes principescas, denunciar os vícios principescos, explicar as manobras diplomáticas e as maquinações políticas. $^{49}$
\end{abstract}

De uma certa forma ele quer referendar o antigo testamento, com a história da vida de Herodes. Se o soberano encarna a história, porque encarna a ambivalência da História, deve ter simultaneamente a capacidade de superá-la enquanto local de decadência, no comportamento moral:

\begin{abstract}
Se a figura do governante, no momento em que ele ostenta o seu poder, da forma mais furiosa, simboliza ao mesmo tempo a manifestação da história e a instância que coíbe as suas vicisssitudes, então algo pode ser dito em favor do César sucumbido a seu delírio de poder: ele se torna vitima da desproporção entre a dignidade hierárquica desmedida de que Deus o investiu e a miséria da sua condição humana. ${ }^{50}$
\end{abstract}

A queda de César é o resultado da desproporção que se abre entre as duas realidades, e só pode ser neutralizada com um elemento da mística cristã: o sacrifício: "quando a contragosto da Cúria caiu a teoria teocrática do Estado, foi reconhecida a inviolabilidade absoluta do monarca". E aqui temos uma contradição só explicada pelo cristianismo. O privilégio que lhe dava a condição de permanecer

\footnotetext{
${ }^{46}$ BENJAMIN. ODBA. p. 89. Ursprung... Opus cit. S. 48.

${ }^{47}$ BENJAMIN. ODBA. p. 90 . Ursprung... Opus cit. S. 49.

${ }^{48}$ BENJAMIN. ODBA. p. 86. Ursprung... Opus cit. S. 45.

${ }^{49}$ BENJAMIN. ODBA, p. 86. Ursprung ... Opus cit. S. 45.

${ }^{50}$ BENJAMIN. ODBA. p. 94. Ursprung... Opus cit. S. 52.
}

Tereza de Castro Callado - Pós-Doutora pela USP, Professora da Universidade Estadual do Ceará (UECE), Brasileira, residente em Fortaleza - CE, E-mail: mterecall@yahoo.com.br 
liberado da lei (legibus solutos) ${ }^{51}$ o obriga ao dever de manter a paz (legibus alligatus) ${ }^{52}$ por imposição da dignidade de que é investido: a antítese de João de Salisbury, entre persona publica e privata voluntas, parece conter, por implicação, a distinção entre o Príncipe como pessoa pública e o Príncipe como pessoa particular. Seria de esperar certa afirmação teórica de que o príncipe, como pessoa privada, está sob a Lei, legibus alligatus, ao passo que sua pessoa pública está acima da Lei, legibus solutis (...) Nas passagens do Policraticus aqui discutidas, a tensão interna encontra-se na própria persona publica do Príncipe: como pessoa pública, ele, o príncipe é simultaneamente imago aequitatis e servus aequitatis, senhor e servo da Lei. A dualidade está no cargo em si, uma conclusão a que João de Salisbury era quase obrigado a chegar, com base em duas leis contraditórias do Corpus Romano, a lex regia e a lex digna". ${ }^{53}$ Assim, ao estoicismo clássico são justapostos elementos onto-teológicos da moral cristã que interferem, com sua força, na vontade real. Benjamin cita Stifter para falar da atuação silenciosa da moral. Assim como na natureza, as leis gerais atuam de forma silenciosa e contínua, e o que se manifesta no mundo, constitui apenas uma exteriorização isolada dessas leis, também a lei moral atua de forma silenciosa e viva na alma de cada um, em uma transferência contínua de homem para homem, e o milagre do momento, nos atos que ocorrem, são apenas as pequenas marcas de uma força geral". ${ }^{54} \mathrm{O}$ drama barroco mostra um hiato na tortura de sua forma que apela também com a tentativa de conciliação desses elementos: radicalização de uma visão de mundo imposta pela absolutização de elementos que compõem o Estado e o movimento natural da vida" ${ }^{55}$ Neles Benjamin mostra a antítese do poder: por um lado, a tirania liberada pelo conceito de absolutismo, por outro o martírio, sem o qual não se restaura a paz e o equilíbrio no reino. Em Os Dois Corpos do Rei, Kantorowicz comenta o pensamento de Egídio Romano, discípulo de Tomás de Aquino para quem a lei positiva está abaixo do monarca e a lei natural está acima dele. ${ }^{56}$ Quando a esse aspecto ambíguo da lei não havia desacordo entre juristas e teólogos pois o rei enquanto lei está sujeito à

\footnotetext{
${ }^{51}$ Outra vez temos que recorrer a Kantorowicz para explicar a condição legibus solutos que influencia o conceito de sobernia: "João de Salisbury não rejeitava a validade essencial da máxima do Direito Romano que proclama o Príncipe como leglibus solutus, pois concebe o mesmo como de fato, livre das amarras da lei. Isso não quer dizer contudo que esteja autorizado a praticar o mal. Está livre das amarras e restrições da lei, da mesma forma como deve estar livre das algemas do pecado. Ele é livre e legibus solutos porque "deve agir comn base em seu sentido inato de justiça e porque está obrigado ex-officio a venerar a Lei e a Eqüidade por amor à própria justiça e não por temor de punição. Não tem culpa quando derrama sangue por sua capacidade de juiz, pois o que ele faz em sua jurisdição, faz como "ministro da utilidade pública" e em benefício do bem comum. É e atua como uma persona pública. E nessa capacidade deve considerar todas as questões em função do bem estar da res publica, e não de sua privata voluntas. Dessa maneira, quando o Direito Romano sustenta que a voluntas do príncipe tem força de Lei, a referência parece ser feita não a suas vontades particulares, mas a voluntas nele ativa como persona publica. Como pessoa publica portanto o rei atende à utilidade pública e conseqüentemente, o portador da imago aequitatis tornase, ao mesmo tempo, o servo da Eqüidade - aequitatis servus est princeps". KANTOROWICZ. Opus cit. p. 76.

${ }^{52}$ KANTOROVICZ. Os Dois Corpos do Rei. Opus cit. 76ª

${ }^{53}$ KANTOROWICZ. Os Dois Corpos do Rei. Opus cit. p. 77.

${ }^{54}$ BENJAMIN. "Karl Kraus" IN Illuminationen. Opus cit. 340.

${ }^{55}$ Nesse sentido é o comentário de Marramao MARRAMO Giacomo. Poder e Secularização (trad. Guilherme Alberto Gomes de Andrade), São Paulo, UNESP, 1995. p. 94.

${ }^{56}$ KANTOROWICZ. Ernst. Os dois corpos do rei - um estudo sobre teologia política medieval (Trad. Cid Knipel Moreira), São Paulo, Companhia das Letras, 1998. p. 95.
}

Tereza de Castro Callado - Pós-Doutora pela USP, Professora da Universidade Estadual do Ceará (UECE), Brasileira, residente em Fortaleza - CE, E-mail: mterecall@yahoo.com.br 
Razão. ${ }^{57}$ Nesse sentido é o comentário de Marramao:

a aparente restauração da antítese moral-política no século XVIII representa o indicador ideológico (porém num sentido, como veremos, inteiramente diverso daquele tradicional de falsa consciência) do hiato que se abre entre a forma do estado absoluto e a dinâmica expansiva da interioridade.

Essa lacuna não existia na concepção do barroco embora ali a antítese fosse outra: Talvez seja correto dizer que o Príncipe concebido por João de Salisbury "não é um ser humano no sentido comum". Este dado é importante para a compreensão da atitude estóica do monarca barroco. Para Salisbury, o príncipe é perfeição, desde que chegue a ser Príncipe e não tirano. O Príncipe é - à boa moda medieval e, no entanto, em um novo sentido jurídico - precisamente a ideia de Justiça que, em si mesma, está sujeito à Lei e, no entanto, acima da Lei porque é o fim de toda Lei. Não é o príncipe, mas a Justiça que reina por meio de ou em um Príncipe, que é o instrumento da Justiça e, ao mesmo tempo, a lex animata, embora Salibury não cite Justiniano a esse respeito. Tudo isso pode parecer hoje nebuloso e ambíguo. Porém nessa ambigüidade, é possível aprender a reconhecer a gemina persona do rei espelhada pela Lei, bem como a idéia de mediação transferida da esfera ligúrgica para jurídica" ${ }^{58}$ Essa teoria no entanto não é mais compatível com a Razão de Estado, no entanto podemos ver ainda sua luz iluminando o conceito de soberania, no barroco. A imanência que o barroco vê entre história e natureza o faz valorizar a exemplariedade do mundo antigo, sem deixar de atravessar a historia dos mártires e sua dose de sentimento cristão com aqueles elementos didascálicos peculiares ao pensamento medieval. $\mathrm{O}$ tema da tragédia dos mártires está presente até no drama da vida de Herodes, rei dos judeus, o mais alto dos seres criados (der Gipfel der Kreatur) e no entanto vítima da própria loucura, "irrompendo no delírio como um vulcão, destruindo-se e destruindo toda a sua corte" ${ }^{59}$ É nesse sentido que Benjamin comenta sobre o conhecimento da natureza humana. Ela capacita o soberano a lidar com os fatos. O conhecimento de si de Sócrates (gnoti sauton) deve estar presente na alma do soberano para desviar-se das forças enganadoras da imaginação, de que fala Pascal: "a imaginação dispõe de tudo: faz a beleza, a justiça e a felicidade, que é o tudo do mundo. São esses, mais ou menos os efeitos dessa faculdade enganadora" 60 , que na metáfora do governante o ilude com o poder, num desafio para se chegar à verdade. Ela se revela (offenbart) quando o soberano do Trauerspiel assume a posição ex officio no exercício da própria soberania.

\footnotetext{
${ }^{57}$ KANTOROWICZ, Ernst. Os dois corpos do rei Opus cit. p. 96.

58 KANTOROWICZ. Os Dois Corpos do Rei, Opus cit. p. 77.

${ }^{59}$ BENJAMIN, ODBA, p. 94. Ursprung. Opus cit. S. 52.

${ }^{60}$ Pascal sente a necessidade de se corrigir o erro que ele atribui aos sentidos ou à instrução. Considera a imaginação a principal força enganadora e assim sendo ela constitui um obstáculo para o homem chegar à verdade. PASCAL, Blaise. Pensamentos (Org. Michel Autrand. Trad. Dra. Ana Rabaça), Lisboa, Paralelo Editora, 2000. p. 68-70.
}

Tereza de Castro Callado - Pós-Doutora pela USP, Professora da Universidade Estadual do Ceará (UECE), Brasileira, residente em Fortaleza - CE, E-mail: mterecall@yahoo.com.br 


\section{REFERÊNCIAS}

BENJAMIN. Walter. Ursprung des deutschen Trauerspiels. Suhrkamp. Frankfurt am Main. 1978.

- Origem do drama barroco alemão (Trad. Sérgio Paulo

Rouanet), São Paulo, Brasiliense, 1984.

. Gesammelte Schriften, Frankfurt am Main, Suhrkamp, 1991.

BODIN. Jean. Los seis libros de la Republica (Trad. Pedro Bravo Gala. Madrid, Technos, 2000.

BOLLE, Willi Org. e Prefaciador dos textos de Benjamin), Documento de Cultura, Documento de Barbárie, São Paulo, Cultrix, 1986.

BOLZ, Norbert. Und VAN REIJEN, Willem. Walter Benjamin. Frankfurt/New York. Campus Verlag, 1991.

BRUN. Jean. O Estoicismo (Trad. João Amado), Edições 70, Lisboa, 1986.

BUTLER, Judith, Mecanismos Psíquicos del poder - teorias sobre la sujeción (Trad. Jacqueline Cruz), Valéncia, Ediciones Catedra, 2001.

DERRIDA, Jacques. Gesetzeskraft - der Mystische Grund der Autorität, Frankfurt, Suhrkamp, 1996.

DEITERS. Franz-Joseph., Allegorie, Moderne, Drama - Versuch einer Grundlegung im Anschluss an Walter Benjamin“ in: Drama im Augenblick seines Sturzes. Berlin, Erich Schmidt Verlag, 1999.

FABER. Richard und BOLZ, Norbert W. (Herausgeber) Antike und Moderne. $\mathrm{Zu}$ Walter Benjamins „Passagen“Würzburg, Königshausen und Neumann, 1986.

HABERMAS, Jürgen. Politik, Kunst, Religion. Essays über zeitgenössigen Philosophen, Stuttgart, Reclam, 2001.

HEIL, Susanne, Gefährliche Beziehungen - Walter Benjamin und Carl Schmitt. Stuttgart, Metzler, 1986.

KANTOROWICZ, Ernst. Os dois Corpos do Rei - um estudo sobre teologia politica medieval (Trad. Cid Knipel Moreira). São Paulo, Companhia das Letras, 1998.

KLIBANSKY, Raymond. PANOFSKY, Erwin, SAXL, Fritz. Saturne et la Mélancolie. Paris, Editions Gallimard, 1989.

LIENKAMP, Christoph. Messianische Ursprungsdialektik - die Bedeutung Walter Benjamin für Theologie und Religionsphilosophie, Frankfurt, IKO, 1998.

LUTERO, Martinho. Da liberdade do Cristão (Trad. Erlon José Paschoal e Carlos 
Eduardo Jordão Machado, São Paulo, UNESP, 1998.

LUTERO e CALVINO. Sobre a autoridade secular e sobre o governo civil (Trad. Hélio de Marco Leite de Barros e Carlos Eduardo Silveira Matos). São Paulo, Martins Fontes, 1995.

LUTHER. Martin Luther - mit Selbstzeugnissen und Dilddokumenten dargestellt von Hanns Lilje. 23a . Auflage, Reinbeck bei Hamburg, Rowohlt Taschenbuch Verlag. 2002.

MATOS, Olgária Chain Féres. Os arcanos do inteiramente outro - a Escola de Frankfurt, melancolia e revolução, São Paulo, Brasiliense, 1989.

MÉCHOULAN, Henry (Org.) L’Etat Baroque 1610-1652. Préface de André Robinet, Paris, Vrin, 1985.

RICHARD, Lionel. A República de Weimar 1919-1833. São Paulo, Companhia das Letras, 1988.

SCHMIDT BIGGEMANN. Wilhelm. Blaise Pascal, München, Verlag C.H. Beck, 1999.

SCHMITT, Carl. Politische Teologie - Vier Kapitel zur Lehre von der Souveränität, Berlin, Duncker \& Humblot, 1996.

SCHOLEM. Gershom. Walter Benjamin und sein Engel - vierzehn Aufsätze und kleine Beiträge. Suhrkamp Verlag, Frankfurt am Main. 1983.

STRAUSS, Leo, Droit Naturel et Histoire, Paris, Flammarion, 1986.

WISMANN, Heinz. Walter Benjamin et Paris - (Études réunis et presentées par Heinz Wismann), Paris, Cerf, 1986. 